\title{
O CONTROLE JUDICIAL CONTRAMAJORITÁRIO E A PRESERVAÇÃO DA HEGEMONIA DA ELITE DOMINANTE: UMA ANÁLISE CRÍTICA PARA A AMPLIAÇÃO DA DEMOCRACIA PARTICIPATIVA NO BRASIL
}

\section{${ }^{1}$ Carla Vladiane Alves Leite ${ }^{2}$ Valmir César Pozzetti}

\section{RESUMO}

O objetivo desta pesquisa é discutir o ativismo judicial que se iniciou nos Estados Unidos da América e ganha força em outros países da América do Sul, como o Brasil, onde o Poder Judiciário vem ganhando força para decidir diversos casos nos últimos anos, desencadeando o fenômeno da judicialização da política. A judicialização acaba gerando Poder demais nas mãos do judiciário, que pode ser utilizado para satisfazer uma elite dominante.

Palavras-chave: Controle judicial, Preservação da hegemonia, Democracia participativa

\section{EL CONTROL JUDICIAL DE LA CONTRAMAJORITÁRIO Y LA PRESERVACIÓN DE LA HEGEMONÍA DE LA ÉLITE DOMINANTE: UN ANÁLISIS CRÍTICO PARA LA EXPANSIÓN DE LA DEMOCRACIA PARTICIPATIVA EN BRASIL}

\section{RESUMEN}

El objetivo de este trabajo es discutir el activismo judicial que comenzó en los Estados Unidos de América y las ganancias de fuerza en otros países sudamericanos, como Brasil, donde el poder judicial está ganando fuerza para decidir varios casos en los últimos años, desencadenando el fenómeno de la judicialización de la política. Se produce esa judicialización generar demasiado poder en manos del poder judicial, que puede utilizarse para satisfacer a una élite dominante.

Palabras-claves: Control judicial, Preservación de la hegemonía, Democracia participativa

\footnotetext{
1 Doutoranda em Direito Econômico Socioambiental pela Pontifíca Universidade Católica - PUC do Paraná, Brasil. Pesquisadora pela Universidade Regional do Cariri - URCA Ceará, E-mail: carla_vladiane@ hotmail.com (Brasil)

2 Doutor em Direito, Ambiebtal pela Université de Limoges - UL, França. Professor Adjunto da Universidade Federal do Amazonas - UFAM, Brasil. E-mail: v__pozzetti@hotmail.com (Brasil)
} 


\section{INTRODUÇÃO}

A presente democracia representativa no Brasil e em vários países do mundo tem diversas limitações governamentais, sociais e de políticas, fatos que fazem essas limitações gerarem inúmeros problemas, principalmente à regra da maioria, já que em muitos casos, deixa a minoria sem a resolução de seus direitos nos textos constitucionais.

Baseado nisso, o modelo de controle judicial, o "judicial review", modelo que os Estados Unidos da América - EUA vêm seguindo, tem se instalado nos Estados

Democráticos de Direito, onde os processos e decisões são submetidos ao judiciário, no caso dos EUA à Corte Suprema, o qual faz o controle de constitucionalidade para se decidir questões polêmicas ou não decididas especificamente por leis, ou seja, há uma transferência de poder para o judiciário decidir casos como última instância ou última palavra.

Portanto, essa transferência de poder para o judiciário vem ocorrendo não apenas em decisões democráticas ou constitucionais, como também em decisões políticas, gerando com isso o ativismo judicial e a judicialização da política.

Como um dos argumentos de defesa das minorias, o que para muitos é visto como um avanço, esse modelo é defendido por alguns estudiosos e pesquisadores no tema, com o argumento de que as leis não fazem a defesa de assuntos polêmicos e que ainda incomodam a sociedade, porém várias teorias criticam o caráter dessas decisões, as chamando de caráter contramajoritário do controle de constitucionalidade judicial, trazendo assim argumentos diversos da chamada objeção contramajoritária.

Diante do tema, portanto, faz-se necessário o debate a partir da visão de Roberto Gargarella, o qual é um dos grandes pesquisadores e crítico do tema da prática jurisdicional relacionada à democracia, à participação e suas representações na política, às teorias de debates sobre a justiça e do constitucionalismo, principalmente em seu desempenho pelo poder judiciário nas relações de democracia atuais.

Gargarella traz o controle judicial em um rol de diálogo na constitucionalidade de leis, papel esse exercido pela Suprema Corte, a qual 
tem a tarefa de interpretação para repensar os direitos sociais e de encarar de maneira diversa a prestação constitucional da minoria.

Porém, esse modelo não é apenas de vantagens para a defesa dos excluídos, já que conforme Gargarella e Ran Hirschl, que trazem algumas críticas ao modelo apresentado nos EUA, ele traz uma série de problemas a serem pensados.

Ran Hirschl desenvolve a tese da preservação da hegemonia por parte das elites políticas dominantes, as quais detêm o poder em suas mãos e que controlam as decisões judiciais aos seus interesses econômicos, políticos e sociais.

Por conta disso, há, portanto a preocupação no Brasil de se analisar o tema, já que ao se deparar com o assunto, pode-se verificar na Constituição e no Judiciário situações citadas pelos pesquisadores em questão, onde há a resolução de questões sociais diversas, sendo por isso chamado esse sistema de "supremocracia".

Portanto, para se analisar esse sistema no Brasil, será feita a análise com o diálogo das críticas nas teorias dos dois autores e pesquisadores no tema apresentado para se tentar entender o desempenho do Supremo Tribunal Federal em decidir casos sociais e políticos e sua dinâmica na relação com a sociedade.

\section{CRÍTICAS AO CONTROLE JUDICIAL}

Após a Segunda Guerra Mundial, começou-se a desconfiar dos regimes democráticos que eram implantados na época, pois os atos do Poder Legislativo em união ao Poder Executivo estavam oprimindo os cidadãos por meio das leis que eram editadas, as quais ofendiam a dignidade da pessoa humana na maioria das vezes.

A partir da decisão do caso Marbury x Madison, o Poder Judiciário vem se impondo para decidir situações de difíceis resoluções, como no caso em questão, onde a Suprema Corte dos EUA trouxe uma situação inédita, ao afastar a lei ao caso concreto para se evitar uma tensão política entre os poderes Legislativo e Judiciário, declarando a referida lei como inconstitucional.

\footnotetext{
${ }^{1}$ Nome dado pela Doutrina dominante em razão da super democracia em resolver todo tipo de assunto.
} 
O referido caso trata-se da eleição presidencial dos EUA de 1800, onde Thomas Jefferson derrotou John Adams. Após a derrota, John Adams resolveu nomear vários juízes em cargos relevantes, para se manter certo controle sobre o

Estado. Entre os cargos relevantes nomeados se encontrava William Marbury, nomeado Juiz de Paz.

O secretário de justiça de John Adams, devido ao curto espaço de tempo, não entregou o diploma de nomeação a Marbury, por conta disso, ao sair do poder e ao assumir Jefferson como presidente, seu novo secretário de justiça James Madison, se negou, a pedido de Jefferson, a intitular Marbury como o juiz de paz.

Porém, Marbury apresentou um Mandado de Segurança perante a Suprema Corte, onde exigia a entrega do diploma. Ao ser relatado o processo, pelo Presidente da Suprema Corte, Juiz John Marshall, em 1803, ele concluiu, segundo interpretação própria, que a lei federal que dava competência à Suprema Corte para emitir mandamus contrariava a Constituição Federal.

Como a lei que dava competência a Suprema Corte era inconstitucional, não cabia à Suprema Corte decidir o pedido do mandamus impetrado por Marbury, não o satisfazendo no interesse buscado.

Essa decisão, porém, não trouxe prejuízos para nenhum dos poderes, pelo contrário, foi politicamente benéfica para ambos, pois versava sobre a competência da Suprema Corte, fazendo a partir de então, parte do cotidiano da pauta da Suprema Corte a decisão desses tipos de casos, o que mais tarde foi se expandindo para outras cortes no mundo inteiro.

Porém, na segunda metade do século $\mathrm{XX}$, começou-se a preocupação com os limites do Poder Judiciário, ao julgar os casos em defesa da Constituição face aos poderes Legislativo e Executivo, instalando então a expressão "ativismo judicial", que se trata da conduta do Poder Judiciário ao julgar com a defesa da efetividade do princípio da supremacia constitucional sob seu entendimento.

Essa prática, porém, veio a trazer a judicialização das questões políticas que antes era matéria somente do Poder Executivo e Legislativo, passando a gerar um desestímulo político, levando o Poder Judiciário à sua expansão, principalmente em casos polêmicos. 
Esse ativismo judicial não é submetido ao controle popular e por conta disso, alguns pesquisadores no tema sustentam que a vontade da maioria estaria prejudicada por agentes antidemocráticos e de grupos elitistas de magistrados, fazendo assim, o povo ter que se submeter à decisões autoritárias e arbitrárias.

\section{A Atuação Contramajoritária}

O presente assunto é um tanto controverso, pois conforme Roberto Gragarella (1997), que se trata de um pesquisador e grande jurista latino americano da modernidade, onde vem se destacando nos estudos realizados, afirma que há a dificuldade de se defender o controle judicial das leis, citando três argumentos os quais ele descreve como o primeiro de "argumento histórico", o qual significa que as constituições não refletem a vontade do povo, pois se trata de um processo antidemocrático, na qual a participação é limitada por um pequeno grupo seleto de pessoas, porém o próprio Gargarella destaca a fragilidade desse argumento em relação ao processo constituinte NorteAmericano, já que se pode verificar o respeito da vontade da maioria nesse processo.

Como segundo argumento, Gargarella traz o "argumento intertemporal" que se trata da crítica da possibilidade de gerações passadas controlarem com normas que não podem ser modificadas ou de fácil alteração para as próximas gerações.

Por fim, um último argumento apresentado pelo autor é o "argumento da interpretação" que traz a ideia de que os juízes ao interpretarem e aplicarem a Constituição não agem declarando a vontade preestabelecida dos constituintes e sim o consenso popular sobre o texto que se sujeitou, porém com a interpretação e a criatividade acompanhadas da indeterminação semântica dos significados da

Constituição, trazendo assim, aos juízes um poder extraordinário, cuja titularidade é impetrada pela democracia contemporânea, a qual deveria ser atribuída ao povo.

Conforme Eros Roberto Grau (2008, p. 161): 
Em síntese: a interpretação do Direito tem caráter constitutivo - e não, pois meramente declaratório - e consiste na produção, pelo intérprete, a partir de textos normativos e dos fatos atinentes a um determinado caso, de normas jurídicas a serem ponderados para a solução deste caso, mediante a definição de uma norma de decisão. Interpretar / aplicar é dar concreção[= concretizar] ao direito.

Em relação à democracia da maioria, pode-se verificar que a regra da maioria traz dúvida em relação à própria democracia, pois nem sempre a regra da maioria é presente em regimes democráticos como o exemplo do Grande Conselho do Fascismo como órgãos não democráticos regidos pelo princípio da maioria.

Porém, essa regra é o fundamento da democracia representativa que em todo caso deve ser levado em consideração, mas existem matérias que não devem ser submetidas ao princípio majoritário, já que há a necessidade de proteção das minorias vencidas.

Contudo, a adoção do regime representativo através do princípio da maioria tem o mecanismo de reduzir os riscos e custas a partir de decisões coletivas da maioria, não trazendo benefícios à minoria.

Por conta disso, o Controle de Constitucionalidade vem opinar com a instituição que assegura o direito das minorias vencidas e da democracia, pois protege e corrige as imperfeições do sistema majoritário, pois cabe à Constituição proteger os direitos fundamentais, mesmo contra a vontade da maioria, protegendo então a minoria, concretizando isso através do Poder Judiciário, ou melhor, do Controle de Constitucionalidade.

Essa situação vem proteger a própria democracia de situações de paixões e interesses em meio às circunstâncias desestabilizadas, tendo então, o poder de autolimitação do poder Constitucional, que tem um procedimento diferenciado e mais dificultoso de se alterar matérias fundamentais que tomam condições existenciais da própria democracia.

Essa circunstância do controle judicial de constitucionalidade de leis, embora muitas vezes contra a vontade da maioria não se trata de antidemocrática e sim contramajoritária, por exercer a democracia constitucional, representando a garantia à democracia e uma proteção às minorias, não sendo então, um limite para a democracia.

Por conta disso, o Poder Judiciário é visto como o Poder Garantidor da noção de democracia ou de corretor dessa democracia, por seu caráter 
contramajoritário, pois a privilegiada função do Poder Judiciário é de ser um órgão com suas garantias de independência, onde há a possibilidade de se ferir, inclusive, a constitucionalidade dos Poderes Executivo e Legislativo, onde há o maior número de casos de normas com ofensas à constitucionalidade, por isso, é o motivo que faz esse poder o melhor para a tarefa de fiscalizar a Constituição, não cabendo essa tarefa aos próprios fiscalizados, ou seja, Legislativo e Executivo, pois não age o Poder Judiciário pela maioria, já que em razão de serem eleitos os poderes Executivos e Legislativos estão mais sujeitos à opinião pública, e com isso mais suscetíveis de concretizar o clamor público em momentos de instabilidade, contrariando, portanto, a própria constituição.

Porém, a realidade conforme Gargarella não traz só benefícios, há problemas na defesa desse mecanismo, pois o poder nas mãos do judiciário pode gerar o ativismo em excesso, fazendo os juízes se tornarem detentores do poder e com isso dele abusar.

\section{A Preservação da Hegemonia da Elite Dominante e a Problemática em torno do Controle Judicial}

Em relação à transferência de poder para se decidir diversos casos para

Poder Judiciário, Ran Hirschl (2007) é outro autor e pesquisador que critica e é contra esse controle, pois traz a ideia de juristocracia, que é justamente esse poder de decidir do judiciário que vem crescendo no mundo todo com a globalização, incluindo os países onde havia uma tradição na soberania do parlamento.

Como resultado desse poder é a judicialização da política, onde há por partes do judiciário o dilema de resolver assuntos morais, políticos e de políticas públicas, trazendo-se assim a tendência da chamada judicialização da Política.

Essa judicialização tem a função de resolver assuntos polêmicos não tratados no teor das constituições especificamente como no caso de casamento de pessoas de mesmo sexo, o aborto, a adoção de crianças por pessoas de mesmo sexo, a extensão dos direitos religiosos e suas liberdades, as liberdades de expressões e dos direitos à igualdade, dentre outros. 
Com isso, os tribunais, principalmente os dos EUA, tem exercido o papel de elaborador de políticas públicas.

Porém, Ran Hirschl (2007) traz três aspectos dessa política de judicialização, onde a primeira é a judicialização das relações sociais, na qual tudo é determinado por regras e procedimentos jurídicos, o que antes era negociável entre as partes de maneira informal, agora se trata do judiciário. Fato que o autor trata como inseparável do fenômeno da captura das relações sociais e da cultura popular e da apropriação dos conflitos sociais por parte do direito.

O segundo e mais concreto aspecto por Hirschl é o aspecto da expansão da competência de tribunais e juízes quanto à definição das politicas públicas, principalmente em relação a decisões envolvendo direitos constitucionais e da remoção judicial de limites entre os órgãos do estado, ou seja, em relação à separação dos poderes e ao federalismo, pois comumente as cortes vêm decidindo sobre liberdades, privacidades, igualdades formais e outros para aumentar o sentido e reforçar as fronteiras de proteção constitucionais à esfera individual, ou seja, direitos fundamentais, pois há a crença de que direitos judicializados operam com maior força. Além disso, há também a possibilidade de juízes reveem atos administrativos por meio do controle judicial, é a chamada justiça processual.

Como aspecto e face da judicialização da política é o emprego de tribunais e juízes para cuidar da "megapolítica" que são controvérsias políticas centrais que definem e em muitos casos divide a comunidade inteira que se subdividem em judicialização de processos eleitorais, supervisão judicial das prerrogativas do Poder Executivos nas áreas de planejamento da macroeconomia ou da segurança nacional e outros.

Porém, Ran Hirschl (2007) critica o modelo apresentado e lamenta a falta de pesquisas empíricas no tema, já que, conforme o pesquisador e autor, a origem e a consequência do processo de judicialização da política trazem a ideia de preservação da hegemonia por parte das elites dominantes.

Esse processo, conforme o Hirschl, foi observado nos quatro países que o autor fez uma análise do controle judicial, eram eles o Canadá, Nova Zelândia, Israel e África do Sul, onde as elites dominantes que controlavam o parlamento estavam ameaçadas pela emergência de novos partidos 
representando novas forças políticas, passaram então a controlar o poder judiciário.

O autor afirma que as mudanças na ordem econômica também ajudam a gerar a transferência de poder de forma intencional para o Poder Judiciário pelas elites políticas que se veem ameaçadas, porém ainda dominantes do poder, onde são apoiados por grupos econômicos liberais que através da constitucionalização de direitos têm um meio de aumentar a desregulamentação da economia e de promover os membros das cortes que querem aumentar suas influências e privilégios internacionais.

Ran Hirschl (2007) chamou esse fenômeno de revolução constitucional e fez a análise antes e após esse fenômeno e concluiu que os efeitos têm sido pouco significativos para se garantir os direitos positivos e coletivos, que são aqueles que exigem a atuação estatal como na saúde, na educação, no trabalho e outros, porém em relação aos direitos negativos, que são aqueles que impõem as restrições à ação estatal tiveram a maior efetividade, já que impedia o Estado de interferir na atividade econômica e na vida privada como o direito à expressão, o devido processo criminal, a igualdade formal sobre a preferencia sexual e outros.

Por conta disso, Hirschl deixa claro que a transferência de poder para o judiciário que permitiu aos juízes das cortes constitucionais interferirem em questões morais e políticas de difíceis resoluções não poderia ocorrer sem a ajuda das elites políticas, pois elas decidem para quem vai o poder decisório e as mesmos transferem para as cortes, mesmo sabendo que o processo pode ser irreversível e que há riscos de julgarem diferente das suas preferencias ideológicas e de seus interesses políticos, econômicos e sociais.

Porém o autor, nas suas pesquisas, pode chegar à conclusão que tem ocorrido esse fato nos países analisados, ou seja, as cortes julgam conforme as elites almejam.

Com isso, Hirschl conclui que a constitucionalização e a revisão judicial por se tornarem global, já que tudo é passível de judicialização, é preocupante e fazem dos juízes os agentes que fazem as politicas públicas sem qualquer ação ou escolha do povo, já que os juízes não são eleitos e nem tem responsabilidade política, porém estão se tornando a principal forma de decisão e de resolução de questões de ordem democrática. 


\section{A DEMOCRACIA PARTICIPATIVA E A IDEIA DE LETIGIMIDADE}

A teoria política define a democracia como um conceito mínimo de regime político, o qual garante os direitos civis e o sufrágio universal.

A partir do século XIX, esse foi o conceito aceito nos países mais ricos e de democracia pelos liberais, com o intuito de limitar a participação do povo nas eleições de representantes, pois assim o povo não teria tanto poder.

Porém, a democracia mínima em seu conceito não parou nisso, já que havia a resistência do povo para se ter uma democracia com definição e conceito que fosse realmente do povo, o que gerou a democracia representativa após a segunda guerra mundial.

Durante uma grande parte do século $X X$, acreditava-se que a democracia representativa era o modelo ideal para os cidadãos, pois traz a ideia de liberdade e igualdade para todas as pessoas, sendo isso o verdadeiro conceito de democracia.

A Democracia dinamitou os velhos quadros sociais, a cidadela dos privilegiados, tabus e preconceitos, em que se encastelava a sociedade feudal. Destruiu impérios, coroas ou tiranias, que pesavam como uma cadeia de ferro sobre os pulsos do homem do povo e modelou uma nova forma de sociedade e de governo. (FERREIRA, Luís Pinto. Princípios Gerais do Direito Constitucional Moderno. Ed. Saraiva, SP, 1990)

Porém, o século XX chegou ao fim e com mais de cem anos de democracia representativa, pode-se verificar que a democracia representativa é falha e está em crise.

A crise citada sobre a democracia representativa trata-se da dificuldade dos representantes do povo identificar e atender as vontades e demandas da sociedade, por isso, tem surgido a organização da sociedade para cobrar e exigir de maneira mais efetiva a resolução de questões, principalmente nas mais complexas.

Os mecanismos e instituições de democracia representativa estão cada vez mais limitados e menos efetivos, por isso, novos e modernos meios necessitam se instrumentalizar para a democracia de controle e participação de poder pelo povo para a efetivação da atuação da vontade deste.

Por conta disso, o conceito de democracia vem mudando e tornando diferente a sua trajetória, para tentar responder os anseios da sociedade. 
A democracia participativa vem como resposta para essas demandas, onde ocorre de forma semidireta, pois não desconsidera os representantes, porém dá ao povo a oportunidade de se aproximar dos representantes para decidir as políticas públicas e sociais.

A democracia participativa é a possibilidade dos cidadãos interferirem na tomada de decisão e no controle do poder, pois os cidadãos tem acesso aos representantes eleitos em relação aos assuntos de sua pertinência e não somente nas eleições, como ocorre na democracia representativa.

A democracia representativa é a democracia onde o povo se manifesta apenas pelo voto, diferente da participativa que tem a pretensão que se tenha meios de controle pela sociedade sobre a administração, o que ocorre de maneira efetiva, pois se estende a democracia à esfera social.

A democracia nesse regime é o democrático, porém na vertente do principio da participação, onde pode assumir varias formas como o referendo, o plebiscito, que são os mais clássicos, assim como as que propiciam a intervenção no processo de decisão como na iniciativa legislativa, no veto popular, os referendos revogatórios e os recalls.

Friedrich Müller (2006) traz o entendimento de que:

\begin{abstract}
A democracia justifica-se a partir do povo, deve servir ao povo ativo, ao povo enquanto instância de atribuição e ao povo-destinatário, quer dizer, aos titulares dos direitos eleitorais, acrescidos de todos os cidadãos, acrescidos de todas as pessoas no âmbito do seu ordenamento constitucional. A democracia é a forma estatal da inclusão.
\end{abstract}

A democracia participativa, portanto vem a ser um modelo ou um ideal que vem a justificar o exercício do poder político através do debate público entre os cidadãos que são livres e com condições iguais de participações.

Alguns teóricos e estudiosos no tema entendem que a democracia participativa se configura entre a democracia representativa e a direta.

Por democracia participativa podemos entender um conjunto de experiências e mecanismos que tem como finalidade estimular a participação direta dos cidadãos na vida política através de canais de discussão e decisão. A democracia participativa preserva a realidade do Estado (e a Democracia Representativa). Todavia, ela busca superar a dicotomia entre representantes e representados recuperando o velho ideal da democracia grega: a participação ativa e efetiva dos cidadãos na vida pública (SELL, 2006, p. 93). 
Esta democracia traz a ideia da legitimidade das decisões politicas que advêm de processos de discussão, os quais são orientados pelos princípios da inclusão, do pluralismo, da igualdade de participação, da autonomia e da justiça social que conferem um reordenamento da lógica do poder político atuante.

Acontece que, os defensores da democracia participativa argumentam que o real sentido da palavra democracia foi se esvaziando no decorrer dos anos e se tornou apenas a escolha de decisões por parte dos governantes e dirigentes, nas quais a sociedade não participa efetivamente.

Com isso, a democracia participativa iria se justificar para a concretização do controle judicial de constitucionalidade e iria equilibrar os poderes Legislativo,

Executivo e Judiciário, onde através desse diálogo, reafirmar a importância do Poder Legislativo como a voz do povo.

\section{CONSIDERAÇÕES FINAIS}

A Constituição da República Federativa do Brasil de 1988 tem diversos problemas para a efetivação de seus direitos garantidos, principalmente em relação aos mecanismos que viabilizam esses direitos.

Além disso, em muitos casos a lei é omissa quanto a muitos direitos, principalmente aos direitos fundamentais quando há polêmica na sua aplicação em conflito entre eles.

Por conta disso, houve a judicialização dos conflitos sociais e políticos e o ativismo judicial para se resolver casos de difíceis resoluções e em muitos casos, resolução de rumos para a politica pública social através do judiciário por ter que decidir esses casos, podendo cair então no ativismo excessivo e até mesmo nas críticas citadas por Gargarella (1997) e Hirschil (2007), onde não estaria apenas pensando na minoria excluída e sim para satisfazer a vontade e o interesse de uma elite dominante.

Para mudar o rumo dessa atual judicilização de conflitos sociais e políticos, assim como o ativismo judicial, se faz necessária a efetivação da democracia participativa através de sua ampliação de maneira mais intensa, onde as normas da Constituição e as leis passariam a realizar as políticas 
públicas e sociais necessárias por consulta ao povo e dando a ele a oportunidade de se manifestar sobre os assuntos.

Para tanto, deve-se dar melhores condições para o povo se informar sobre a responsabilidade e necessidade de sua participação, além de melhorar os mecanismos para essa atuação do povo.

Essa efetiva participação garantiria ao povo se tornar o verdadeiro detentor do poder de decidir o futuro do país dando-o a voz garantida na Constituição Federal de 1988.

\section{REFERÊNCIAS}

AFONSO DA SILVA, José. Curso de Direito Constitucional Positivo. $27^{\text {a }}$ ed. São Paulo: Malheiros Editores, 2006.

edição, Malheiros, São Paulo, 1992;

- Curso de Direito Constitucional Positivo, 9a . O Estado Democrático de Direito, Revista Forense,

V. 305, Jan/Fev/Mar/89;

ANDRADE, Aparecida de Moura. A participação da sociedade civil no processo legislativo: a contribuição da comissão de legislação participativa da câmara dos deputados. (Monografia de Especialização). Programa de PósGraduação da Universidade de Brasília. Brasília: UnB, 2003.

AVRITZER, Leonardo. Modelos de Deliberação Democrática: uma análise do orçamento participativo no Brasil. In: SANTOS, Boaventura de Sousa (org.). Democratizar a Democracia: os caminhos da democracia participativa. Rio de Janeiro: Civilização Brasileira, 2002.

BARROSO, Luís Roberto. Interpretação e Aplicação da Constituição -

Fundamentos de uma Dogmática Constitucional Transformadora. 4 ${ }^{a}$ ed. São Paulo: Editora Saraiva 2002.

BASTOS, Celso Ribeiro. Curso de Direito Constitucional, 19a edição, Saraiva, São Paulo, 1998.

BENEVIDES, Maria Vitória de Mesquita. A Cidadania Ativa - Referendo,

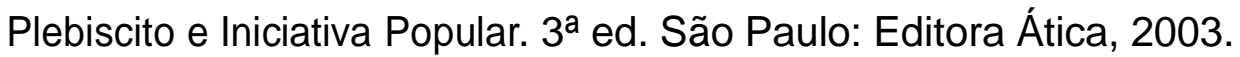

BESTER, Gisela Maria. Direito Constitucional: Fundamentos Teóricos. Vol. I São Paulo: Editora Manole Ltda., 2005.

BONAVIDES, Paulo. Curso de Direito Constitucional, $7^{\text {a }}$ edição, $2^{\mathfrak{a}}$ tiragem, 
Malheiros Editores, São Paulo, 1998.

Teoria Constitucional da Democracia Participativa

- Por um direito constitucional de luta e resistência, por uma nova hermenêutica, por uma repolitização da legitimidade. $2^{\underline{a}}$ ed. São Paulo: Malheiros Editores, 2003.

BRASIL. Constituição da República Federativa do Brasil de 1988. Acesso em 26.06.2015.

CANOTILHO, José Joaquim Gomes. Direito Constitucional e Teoria da

Constituição. Almedina, Coimbra, 1997.

CARRION, Eduardo Kroeff Machado. Apontamentos de Direito Constitucional. Livraria do Advogado, Porto Alegre, 1997.

CRETELLA JUNIOR, José. Elementos de Direito Constitucional. 2ª edição,

Revista dos Tribunais, São Paulo, 1998.

DE SOUZA, Nelson Oscar. Manual de Direito Constitucional. 2 ${ }^{\mathrm{a}}$ edição, Forense, Rio de Janeiro, 1998.

ESPÍNDOLA, Ruy Samuel. Democracia Participativa autoconvocação de referendos e plebiscitos pela população (análise do caso brasileiro).

Estudos Eleitorais. Tribunal Superior Eleitoral, v. 5. n.2, p. 65-87, maio/ago. 2010.

FERREIRA FILHO, Manoel Gonçalves. Direitos Humanos Fundamentais. $2^{\underline{a}}$ Saraiva, São Paulo, 1998;

de 1988. Saraiva, São Paulo, 1990; . Comentários à Constituição Brasileira

FONSECA, Jumária Fernandes Ribeiro. O Orçamento Participativo e a Gestão

Democrática de Goiânia. Dissertação (Mestrado em Desenvolvimento e Planejamento Territorial). Programa de Pós-Graduação em Desenvolvimento e

Planejamento Territorial da Universidade Católica de Goiás. Goiânia, 2009.

GARGARELLA, Roberto A. La dificultad de defender el control judicial de las leyes. Edición digital a partir de Isonomía : Revista de Teoría y Filosofía del Derecho, núm. 6 (abril 1997), pp. 55-70

GRAU, Eros Roberto. A Ordem Econômica na Constituição de 1988. $8^{\text {a }}$ ed. São 
Paulo: Malheiros Editores, 2008. GUTMANN, Amy; THOMPSON, Dennis. Why Deliberative Democracy? Princeton:

Princeton University Press, 2004. (tradução do primeiro capítulo do livro de Bruno Oliveira Maciel).

HIRSCHL, Ran. Towards Juristocracy: the origins and consequences of the new constitutionalism. Constitutional theocracy. Harvard University Press, Cambridge e London, 2007. Capítulo 3. p. 50-99.

LÜCHMANN, Lígia Helena Hahn. Possibilidades e limites da democracia deliberativa: a experiência do orçamento participativo de Porto Alegre. Tese (Doutorado em Ciências Sociais). Instituto de Filosofia e Ciências Humanas da Universidade Estadual de Campinas. Campinas-SP, 2002.

MAGAGNIN, Renata Cardoso. Um sistema de suporte à decisão na internet para 0 planejamento da mobilidade urbana. Tese (Doutorado em Engenharia Civil: Transportes). Escola de Engenharia de São Carlos da Universidade de São Paulo. São Carlos-SP, 2008.

MÜLLER, Friedrich. Democracia e exclusão social em face da globalização. 2006.http://www.planalto.gov.br/ccivil_03/revista/Rev_72/artigos/Friedrich_rev7 2.htm. Acesso em 29.06.2015.

NASSUNO, Marianne. Burocracia e Participação: a experiência do orçamento participativo em Porto Alegre. Tese (Doutorado em Ciências Sociais). Departamento de Sociologia da Universidade de Brasília. Brasília, 2006.

PATEMAN, C. Participação e Teoria Democrática. Rio de Janeiro: Paz e Terra, 1992.

PINTO FERREIRA, Luís - Curso de Direito Constitucional. 8a edição, Saraiva, São Paulo, 1996;

SELL, Carlos Eduardo. Introdução à Sociologia Política: política e sociedade na modernidade tardia. Petrópolis, RJ: Vozes, 2006.

TEMER, Michel - Elementos de Direito Constitucional. 14ª edição, Malheiros Editores, São Paulo 1998.

VIEIRA, José Ribas. Et. al. Ativismo Jurisdicional e o Supremo Tribunal Federal. Trabalho publicado nos Anais do XVII Congresso Nacional do CONPEDI, realizado em Brasília - DF nos dias 20, 21 e 22 de novembro de 2008. http://www.conpedi.org.br/manaus/arquivos/anais/brasilia/15_639.pdf. Acesso em 29.06.2015.

- Verso e reverso: a judicialização da Política e o ativismo judicial no Brasil. Estação Científica (Ed. Especial Direito) Juiz de Fora, V. 01, no. 04 outubro e novembro/2009, p. 44-57.

VIEIRA, Oscar. Os Supremocracia: vícios e virtudes republicanas. 2007. 
O Controle Judicial Contramajoritário e a Preservação da Hegemonia da Elite

Dominante: Uma Análise Crítica para a Ampliação da Democracia Participativa no Brasil

Temas de Direito do Estado.

http://direitoestado.blogspot.com.br/2009/06/supremocracia-vicios-e

virtudes.html. Acesso em 29.06.2015. 